\title{
Research must precede clean-up, DoE warns
}

Boston. A leading official of the US Department of Energy (DoE) warned last week that the department needs to impose a major change in the direction of its \$3-billion-ayear research programme if it is to find a way of clearing up the legacy left by its nuclear weapons research.

But he added that the department's laboratories, which are currently searching for a new mission, are not necessarily the right place for conducting new research into cleanup techniques, as they are too expensive.

There is also evidence that the public is growing impatient with the government's approach to clean-up. This has been reflected in a recent congressional cut of $\$ 400$ million in the Department of Defense's \$2.6 billion clean-up budget for the 1995 financial year, which started this month.

Tom Grumbly, assistant secretary in charge of the clean-up, was addressing a meeting at the Massachusetts Institute of Technology (MIT) on efforts being made by the Department of Defense and Department of Energy. He said that he intends to resist pressure to increase the speed with which contaminated sites are being tackled, preferring to wait until the research has been done to find the right means of doing so.

"We want to titrate the amount of cleanup that we do with the amount of new technology we have coming through," Grumbly said. Clean-up of department sites, which include the entire production chain for US nuclear weapons, would take "not 30 years, but a lifetime," he added. It would require much fundamental research on ways of dealing with chemical and radiation problems.

Calling on scientists to join in the search for new clean-up techniques, Grumbly referred back to the early nuclear work of Niels Bohr, Robert Oppenheimer and Edward Teller. "Their legacy is not finished," he said. Today's scientists have an obligation "to close the circle and apply the same scientific vigour" to the clean-up problem, he said.

Until five years ago, the DoE spent no money on research into clean-up techniques. Such work now accounts for about $\$ 400$ million of the department's $\$ 3$ billion annual research and development budget.

Further expansion will have to come at the expense of other research areas, such as alternative energy sources (also an administration priority), high-energy physics, or nuclear weapons. The last option is more problematic that it sounds, as the US nuclear weapons strategy is to cease production and tests, but maintain capability on the basis of superior research and development.

The department says it is making substantial progress on the clean up of the 160 contaminated sites left by the nuclear weapons programme. "In one year, the programme has gone from being a total failure to at least

offering hope," says Grumbly. Of \$2 billion budgeted for environmental restoration, half goes on "actual remediation" and the rest, he concedes, on the "analysis-paralysis part of the programme", under which the department assesses problems, haggles with regulators and then reassesses them.

From 1 January, Grumbly will inherit

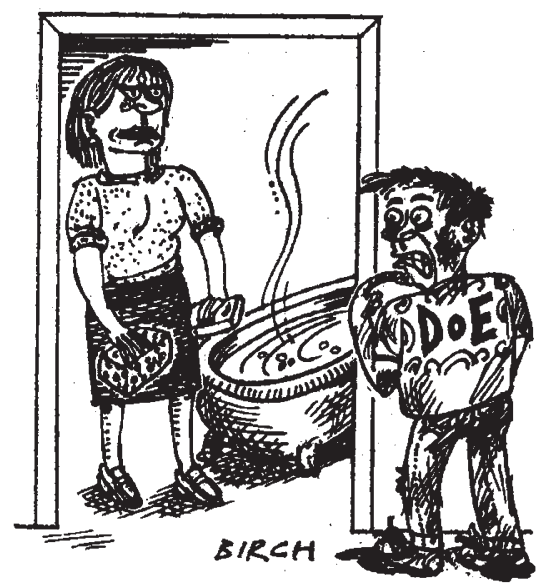

full responsibility for nearly all of these sites and their mission will switch from being available to produce weapons to cleaning themselves up. The budget of his office will account for about $\$ 7$ billion out of the department's $\$ 12$ billion total, and clean-up will displace the nuclear weapons programme as the DoE's largest responsibility.

\section{Cable set to confound HTS critics}

Boston. High-temperature superconductors move closer to real-world application to power transmission this week with the launch of a \$6-million project to build a prototype underground power line.

The project is being mounted jointly by the Electric Power Research Institute (EPRI) - a power industry research collaboration - American Superconductor Corporation of Westborough, Massachusetts, cable company Pirelli, and the laboratories of the US Department of Energy.

Details of the project were announced in Boston by energy department officials and Senator Edward Kennedy (Democrat, Massachusetts). If it fulfils its objective, the project will lead to the economically feasible replacement of existing underground copper power lines in urban areas with lines based on hightemperature superconductivity (HTS).

Success would also confound critics who said the ceramic materials, invented in 1987 by IBM researchers in Switzerland, were too fickle in their conductivity, and too brittle, for such use.

EPRI, which will fund almost half of
The Department of Defense has an equally large non-nuclear clean up plan, part of which has been speeded up under its base closure programme, which allows small, site-specific teams to manage 'fast-track' clean-up. The teams - which each include a military coordinator, an official from the Environmental Protection Agency and a state regulator - have special powers to ensure that plans are carried out.

But the DoE has no such short cut in prospect. All it can do is hope that Congress will have the patience to pay for the research that will eventually allow the nuclear mess to be cleaned up over many decades.

At the same time, several speakers at the MIT conference voiced scepticism about the department's central strategy of winning back public trust, as it is trying to do through an 'openness' campaign led by Hazel O'Leary, the energy secretary.

Todd LaPorte, a professor of politics at the University of California at Berkeley, who is preparing a report for O'Leary on the question of nuclear waste and public trust, reports that "the public has no trust in the department".

Even Grumbly hinted that neither he nor O'Leary is immune to the idea that the Energy Department, as it currently operates, may not be up to the task in hand. "I have serious doubts, some days," that the department can do the clean-up, he says. "And I know the secretary does too."

Colin Macilwain

the project, sees the 30 -metre prototype as a step to upgrading and replacing 2,200 miles of ageing copper trunk power lines under the streets of US cities. By replacing these in situ with superconducting lines of two to five times the powerhandling capacity, power companies could save the costs of re-excavating the lines.

"They've borrowed the retrofit concept from the telecommunications industry, which has been pulling out copper links and putting in optical fiber," said Greg Yurek, a former materials professor at the Massachusetts Institute of Technology who now heads American Superconductor.

The prototype power line will consist of a matrix of superconductors wound around a stainless steel tube, through which liquid nitrogen will flow to keep them cool. Paul Grant of EPRI says this is not seen as a disadvantage, as existing underground copper cables have to be cooled by oil. The challenge in building the prototype will be to produce and machine-wind the superconductor at sufficient quality and satisfactory cost. C. M. 